\title{
El estatuto jurídico del embrión en la Jurisprudencia del Tribunal Constitucional español
}

\author{
Carlos Vidal Prado \\ Profesor Titular de Derecho Constitucional \\ Universidad Nacional de Educación a Distancia
}

Recibido: 02.05.12

Aceptado: 31.05 .12

Resumen: El presente trabajo versa sobre la relevante jurisprudencia del Tribunal Constitucional en relación al estatuto jurídico del embrión, a los distintos niveles de protección del embrión y sobre las importantes consecuencias jurídicas derivadas de este desarrollo jurisprudencial. aborto.

Palabras claves: Tribunal Constitucional, jurisprudencia, embrión, vida,

Abstract: The present work deals with the relevant jurisprudence of the Constitutional Court regarding the legal status of the embryo, the different levels of protection of the embryo. This paper also deals with the important consequences of the jurisprudential development regarding this subject.

Key words: Constitutional Court, jurisprudence, embryo, life, abortion.

La jurisprudencia del Tribunal Constitucional español sobre el estatuto jurídico del embrión tiene como hito principal la STC 53/1985, de 11 de abril, relativa al Proyecto de Ley Orgánica de reforma del art. 417 bis del Código Penal (la primera ley despenalizadora del aborto en España, de 1985). Esta jurisprudencia se ha ido completando, entre otras, con las sentencias 212/1996, de 19 de diciembre relativa a la Ley 42/1998 de 28 de diciembre de donación y utilización de embriones y fetos humanos, o de sus células, tejidos y órganos, y la 116/1999 de 17 de junio en relación con la Ley 35/1988 de 22 de noviembre, sobre técnicas de reproducción asistida.

El Tribunal Constitucional ha ido, de este modo, construyendo una doctrina que ha sentado las bases de la tutela jurídica de la vida del nasciturus. Partiendo del análisis del artículo 15 de la Constitución, que proclama el derecho de "todos" a la vida, entiende que el nasciturus no es titular de ese derecho fundamental, pero sí declara que es "alguien", un tertium esencialmente distinto respecto de la madre con la que se relaciona (STC 53/1985, FJ 5) ${ }^{1}$.

${ }^{1}$ Sobre el estatuto jurídico del embrión en la doctrina y jurisprudencia españolas, puede verse Rubio, R.: “El estatuto jurídico de la vida por nacer”, en D’Aloia (Coord.), Il Diritto e la vita. Un dialogo italo-spagnolo su aborto ed eutanasia, Jovene editore, Nápoles, 2011, págs. 145-169. Asimismo, Alegre Martínez, M. A., "Apuntes sobre el derecho a la vida en España: Constitución, jurisprudencia y realidad”, en Revista de Derecho Político, 53, 2002, págs. 337-360. 
Resulta discutible, sin embargo, y puede entenderse como contradictorio, que tras esta argumentación, en la que se reconoce la existencia de un tercer sujeto, diferente a la madre, Tribunal acabe no reconociendo al nasciturus la titularidad del derecho a la vida, declarando así la legitimidad constitucional del sistema de despenalización del aborto basado en el sistema de indicaciones -terapéutica, criminológica y eugenésica-: "En definitiva, el sentido objetivo del debate parlamentario corrobora que el nasciturus está protegido por el artículo 15 de la Constitución, aun cuando no permite afirmar que sea titular del derecho fundamental". Se trata de un salto argumental cuando menos discutible.

En todo caso, el Tribunal identifica un sujeto digno de protección jurídica (el nasciturus), en cuanto que representa un bien jurídico necesitado de protección, la vida humana, "un devenir, un proceso que comienza con la gestación, en el curso de la cual una realidad biológica va tomando corpórea y sensitivamente configuración humana, y que termina en la muerte; es un continuo sometido por efectos del tiempo a cambios cualitativos de naturaleza somática y psíquica que tienen un reflejo en el status jurídico público y privado del sujeto vital. (...) La gestación ha generado un tertium existencialmente distinto de la madre, aunque alojado en el seno de ésta" (STC 53/1985, FJ 5). De estas afirmaciones del Tribunal se deduce, además, que el no nacido pertenece a la especie humana.

Basándose en ello, concluye que "la vida del nasciturus, en cuanto éste encarna un valor fundamental -la vida humana-garantizado en el artículo 15 de la $\mathrm{CE}$, constituye un bien jurídico cuya protección encuentra en dicho precepto fundamento constitucional" (STC 53/1985, FFJJ 5 y 7). Esta idea se repite en sentencias posteriores, al sostener que "en el caso de la vida del nasciturus, no nos encontramos ante el derecho fundamental mismo, sino, como veremos, ante un bien jurídico constitucionalmente protegido como parte del contenido normativo del art. 15 CE" (STC 212/1996, FJ 3).

Aborda además el Tribunal una justificación de esta tesis, es decir, la de hacer derivar la protección del bien jurídico "vida" de un artículo de la Constitución, el 15, que reconoce un derecho fundamental. Así, expone que "ciertamente, los preceptos constitucionales relativos a los derechos fundamentales y libertades públicas pueden no agotar su contenido en el reconocimiento de los mismos, sino que, más allá de ello, pueden contener exigencias dirigidas al legislador en su labor de continua configuración del ordenamiento jurídico, ya sea en forma de las llamadas garantías institucionales, ya sea en forma de principios rectores de contornos más amplios, ya sea, como en seguida veremos, en forma de bienes jurídicos constitucionalmente protegidos" (STC 212/1996, FJ 3, STC 116/1999, FJ 5).

El Tribunal extiende así la protección constitucional hasta el nasciturus que, sin ser titular del derecho fundamental de todos a la vida, "está protegido por el artículo 15 de la constitución" (STC 53/1985, FFJJ 5 y 7; STC 212/1996, FJ 3), por lo que esa vida "es un bien jurídico constitucionalmente protegido". 
Según esta doctrina, y conforme a la Constitución, no se puede desproteger la vida humana «en aquella etapa de su proceso que no sólo es condición para la vida independiente del claustro materno, sino que es también un momento del desarrollo de la vida misma» (STC 53/1985, FJ 5). El nasciturus es, según el Alto Tribunal, aquel "con expectativa de personalidad" (STC 212/1996, FJ 6), "un ser que en su día puede llegar a ser titular del derecho a la vida, al igual que de los restantes derechos humanos" (STC 212/1996, FJ 3).

En consecuencia, el artículo 15 de la Constitución y la necesidad de proteger la vida del nasciturus, como señalan la sentencias 53/1985, FJ 7 y 212/1996, FJ 3 y FJ 9, "implica para el Estado con carácter general dos obligaciones: la de abstenerse de interrumpir o de obstaculizar el proceso natural de gestación, y la de establecer un sistema legal de defensa de la vida que suponga una protección efectiva de la misma y que, dado el carácter fundamental de la vida, incluya también, como última garantía, las normas penales". Por lo tanto, también el Derecho penal debe proteger la vida del no nacido. Lo contrario entraría en conflicto con la Constitución y con la interpretación que de la misma ha hecho el máximo órgano autorizado para ello, el Tribunal Constitucional.

Esa vida en desarrollo, un devenir que comienza con la fecundación, "no es una realidad única a efectos de su protección jurídica" (STC 53/1985, FJ 5), y por eso el Tribunal entiende que caben diversos niveles de protección. Lo que debe, por tanto, garantizarse en la regulación, es esta protección en todas las etapas de esta vida en desarrollo. Esa protección debe garantizarse suficientemente en cualquier regulación que afecte a cualquier fase de la vida, y precisamente las escasas garantías que incorporaba el primer Anteproyecto de Ley del Aborto fueron las que motivaron la declaración de inconstitucionalidad de la ley. Lo que se puede subrayar, en consecuencia, es la importancia de establecer suficientes mecanismos de protección de la vida, para que la norma sea conforme con lo dispuesto en la Constitución.

También en las citadas sentencias del TC sobre el tratamiento de embriones se admiten diversos niveles de protección, pero partiendo siempre de considerar necesaria esa protección. Así, la sentencia 116/1999, especialmente en el FJ 9, entiende que la protección dada al embrión no transferido (preembrión) es inferior a la del embrión implantado, algo de lo que se deduce que la etapa del preembrión no puede estar exenta de protección jurídica (aunque ésta sea menor que la protección otorgada a otras etapas), y que todas las acciones que se justifican en esta línea deben hacer relación a la reproducción humana para garantizar su constitucionalidad. En el FJ 7 de la STC 116/199 se habla expresamente de la "la protección jurídica que, constitucionalmente, se garantiza a los nascituri". Se hace expresa referencia en esta Sentencia a la STC 212/1996, FJ 5.

Sólo cuando hay conflicto, un choque de intereses, puede el Estado modular o limitar esa protección y eso es lo que ocurre, en el caso del aborto, con el sistema de indicaciones, que excluye la punibilidad de los abortos cau- 
sados en los tres supuestos o indicaciones legales (terapéutico, eugenésico y ético). En todo caso, se trata siempre de una ponderación entre los intereses en conflicto, sin que uno de los intereses prevalezca incondicionadamente sobre el otro.

El Tribunal Constitucional entendió que estaba justificado considerar que en esos casos extremos (peligro para la vida o salud de la mujer, embarazo consecuencia de una violación y riesgo de que el feto pueda nacer con graves taras o malformaciones), a la mujer que aborta no le es exigible otra conducta, luego es razonable no sancionarla penalmente y que en esos casos el Estado renuncie a la tutela penal del no nacido. Esa renuncia a la tutela penal de la vida del no nacido está justificada porque "se trata de graves conflictos de características singulares, que no pueden contemplarse tan sólo desde la perspectiva de los derechos de la mujer o desde la protección de la vida del nasciturus. Ni ésta puede prevalecer incondicionalmente frente a aquéllos, ni los derechos de la mujer puedan tener primacía absoluta sobre la vida del nasciturus, dado que dicha prevalencia supone la desaparición, en todo caso, de un bien no sólo constitucionalmente protegido, sino que encarna un valor central del ordenamiento constitucional. Por ello, en la medida en que no puede afirmarse de ninguno de ellos su carácter absoluto, el intérprete constitucional se ve obligado a ponderar los bienes y derechos en función del supuesto planteado, tratando de armonizarlos si ello es posible o, en caso contrario, precisando las condiciones y requisitos en que podría admitirse la prevalencia de uno de ellos" (STC 53/1985, FJ 9). De acuerdo con estas consideraciones, ninguna vida humana puede quedar a plena disposición de un tercero, porque sería tanto como dar primacía absoluta a los derechos de la mujer sobre la vida del nasciturus.

En ese mismo Fundamento Jurídico 9 sigue diciendo el TC que el legislador debe tener presente la razonable exigibilidad de una conducta y puede también renunciar a la sanción penal de una conducta que objetivamente pudiera representar una carga insoportable. "Existen situaciones singulares o excepcionales en las que castigar penalmente el incumplimiento de la ley resultaría totalmente inadecuado; el legislador no puede emplear la máxima constricción -la sanción penal-para imponer en estos casos la conducta que normalmente sería exigible pero que no lo es en ciertos supuestos concretos".

En el FJ 11 de la STC 53/1985, el Tribunal admite los tres supuestos previstos la actual regulación (terapéutico, eugenésico y ético), por considerar que el recurso a la sanción penal entrañaría la imposición de una conducta que excede de lo que normalmente es exigible a una madre y su familia. Sin embargo, en el FJ 12 de la misma Sentencia justifica la inconstitucionalidad del primer Proyecto de Ley, al entender que debían incluirse algunas garantías más, precisamente para proteger la vida del nasciturus en aquellos supuestos que quedan fuera del nuevo precepto penal, es decir, para evitar abusos. Debía lograrse una protección efectiva, concepto, por cierto, que centró los debates parlamentarios de la nueva y vigente Ley. 
En posteriores Sentencias el TC ha seguido manteniendo que la vida del no nacido, si bien puede ser sometida a ponderación, no puede quedar desprotegida de modo absoluto. Así, las SSTC 212/1996 y 116/1999 se apoyan en la doctrina de la STC 53/1985: como es sabido, el nasciturus no es persona a efectos de determinación de la titularidad del derecho a la vida, pero sí es un bien digno de protección constitucional, por lo que nace la obligación del Estado de dotarle de cierta protección jurídica.

Las citadas SSTC 212/1996 y 116/1999, en la medida en que apoyan la constitucionalidad de los preceptos impugnados en la distinción entre fetos viables y no viables, están ponderando, en la línea de lo apuntado en la STC 53/1985. Luego se deduce de la jurisprudencia del Tribunal Constitucional (y no sólo de una Sentencia) que el estatuto jurídico-constitucional del no nacido (bien digno de protección jurídica) impide una regulación en la que decisión sobre su continuidad vital sea completamente incondicionada. En todo caso, es necesaria siempre una ponderación, que garantice que no existe una desprotección absoluta de una de las dos partes en el conflicto jurídico.

A partir de la construcción jurisprudencial de la STC 53/1985, en definitiva, el TC intenta mantener su coherencia, a la hora de abordar un cierto estatuto jurídico del embrión. De este modo, sostiene que no existe titularidad de derecho subjetivo a la vida propiamente dicho antes del nacimiento. No obstante, según el TC, esto no impide que en la vida prenatal esté presente un bien, la vida humana, que debe protegerse por el ordenamiento, como parte de la normativa constitucional. Ello implica una doble obligación del Estado respecto a la vida prenatal, la de abstenerse de interrumpir u obstaculizar el proceso natural de gestación y la de establecer un sistema legal para la defensa de la vida que suponga una protección efectiva de la misma.

En cuanto al bien jurídico digno de protección, es decir, la vida, se define como un devenir desde la fecundación y en esta línea, el Tribunal entiende que caben diversos niveles de protección (sin que, por cierto, pueda existir ninguna fase del desarrollo de esa vida que quede privada absolutamente de protección). También en las sentencias del TC sobre el tratamiento de embriones, como hemos visto, se admiten diversos niveles de protección, pero al fin y al cabo se considera necesaria esa protección. Al margen de que resulte discutible la terminología utilizada (la distinción entre embrión y preembrión), que se aparta de la terminología científica y que no es acogida por las legislaciones de los países de nuestro entorno, lo cierto es que se afirma que la etapa del preembrión no puede estar exenta de protección jurídica, y que todas las acciones que se justifican en esta línea deben hacer relación a la reproducción humana para garantizar su constitucionalidad.

El propio Tribunal reconoce en la sentencia 53/1985 (FJ 5), que la inclusión en el artículo 15 CE de la expresión "Todos tienen derecho a la vida", obedeció, durante la tramitación parlamentaria, a la voluntad mayoritaria de lograr la plena y eficaz protección del nasciturus, de modo que no quedase fuera del ámbito de protección de dicho precepto. Además, se evitó utilizar la 
palabra "persona", para evitar que "se entendiera incorporado el concepto de la misma elaborado en otras disciplinas jurídicas específicas, como la civil y la penal, que, de otra forma, podría entenderse asumido por la Constitución"2.

En todo caso, se ha sostenido que la consideración conjunta de los artículos 10.1 (dignidad de la persona, libre desarrollo de la personalidad) y 15 (Todos tienen derecho a la vida) de la Constitución, permite considerar superada la disyuntiva terminológica todos/las personas; pues lo importante, en definitiva, es la voluntad inequívoca del constituyente de no excluir a ningún ser humano del reconocimiento del derecho fundamental a la vida ${ }^{3}$. En el FJ 5 de la STC 53/1985 se dice que "la vida del nasciturus, en cuanto éste encarna un valor fundamental -la vida humana- garantizado en el artículo 15 de la Constitución, constituye un bien jurídico cuya protección encuentra en dicho precepto fundamento constitucional". A continuación, el Tribunal concluye que "el sentido objetivo del debate parlamentario corrobora que el nasciturus está protegido por el artículo 15 de la Constitución, aun cuando no permite afirmar que sea titular del derecho fundamental". Habría que preguntarse, no obstante, si es tan claro y evidente que puede negársele al nasciturus la titularidad de ese derecho fundamental, como el Tribunal hace en las SSTC 212/1996 de 19 de diciembre y 116/1999 de 17 de junio. En el FJ 3 de la primera de estas sentencias se afirma que el artículo 15 de la Constitución "reconoce como derecho fundamental el derecho de todos a la vida, derecho fundamental del que, como tal y con arreglo a la STC 53/1985, son titulares los nacidos, sin que quepa extender esa titularidad a los nascituri". De modo más claro, unas líneas más adelante, se habla del "derecho fundamental de todos, es decir, de los nacidos, a la vida".

La doctrina "mayoritaria" del Tribunal Constitucional reflejada en esta jurisprudencia resulta, en este sentido, claramente criticable, en cuanto que, como señala en su voto particular a la STC 53/1985 el Magistrado RUBIO LLORENTE, la vida es "algo más que un valor jurídico", no encontrándose, por tanto, entre esos "valores abstractos que la Constitución efectivamente proclama".

En coherencia con esta jurisprudencia, el Tribunal Constitucional llega a otra consecuencia: en la citada sentencia 116/1999, FJ 4, puede leerse que

${ }^{2}$ Uno de los padres constitucionales, Gabriel Cisneros, en el prólogo al libro de A. OLLERO, Derecho a la vida y derecho a la muerte, pág. 11, corrobora esta afirmación, al sostener que "se eludió el sujeto 'persona' o 'personas' para evitar la transposición del más restrictivo concepto elaborado por el derecho civil". Es interesante traer a colación lo que dice después: "puede lamentarse, con la experiencia sobrevenida, que no se abordara una inédita configuración de la persona comprensiva del nasciturus. Mas, aún sin evocar las dificultades políticas del propósito, semejante tarea parece más propia de la integración interpretativa jurisdiccional -es lo que pudo haber hecho la sentencia 53/1985-que de la concisa dicción de la norma".

${ }^{3}$ Miguel Ángel ALEGRE MARTÍNEZ, La dignidad de la persona como fundamento del Ordenamiento constitucional español, Universidad de León, 1996, págs. 49 y 92 ss. 
la disposición impugnada (Ley 35/1988 de 22 de noviembre, sobre técnicas de reproducción asistida), al igual que la Ley 42/1988 (de donación y utilización de embriones y fetos humanos, o de sus células, tejidos y órganos) "no desarrolla el derecho fundamental a la vida reconocido en el artículo 15 CE"; concluyendo así que dicha norma "no vulnera la reserva de Ley Orgánica exigida en el artículo 81.1 CE". A la vista del resultado al que se llega (que de alguna manera reduce el nivel de garantía de un derecho fundamental como la vida), pensamos que tiene toda su justificación un replanteamiento de los fundamentos últimos de esta jurisprudencia constitucional. 